\title{
PSYCHOSOMATIC NON-ARTICULAR RHEUMATISM
}

\author{
BY \\ E. P. EDMONDS
}

It seems now to be fairly widely agreed that emotional factors are relevant to the study of rheumatism, and particularly of non-articular rheumatism or fibrositis. The Horder Report (1941) stated that "Worry, anxiety, mental shock, can be often recognized as promotive of rheumatic disease". The relationship is perhaps more often expressed as a matter of differential diagnosis between muscular pains of psychoneurotic origin and what is described as " true rheumatism ". But quite apart from psychological considerations, there is much controversy as to what constitutes " true " non-articular rheumatism.

\section{Non-articular Rheumatism in General}

Much of the present controversy lies broadly between the exponents of "fibrositis" as a precise clinical and pathological entity and those, more sceptical, who recognize only a vaguer collection of conditions better described as " myalgia ". The word rheumatism has the advantage of its wide recognition by doctors and patients in the description of a certain type of pain, usually with some stiffness and tenderness, of muscle and related fibrous tissue. According to a recent definition (Annotation, Brit. med. J., 1946) the word rheumatism " by derivation implies the defluxion of a morbid humour to the part-that is to say, a local tissue change". While postulating a local tissue change, however, the word is non-committal with regard to the precise nature of this change.

\section{Possible Causative Factors}

Some of the factors generally thought to be concerned in the production of non-articular rheumatism are as follows:

(a) chill from draughts, damp, or excessive sweating;

(b) trauma or strain, acute, as the "crick in the neck" or chronic, as gardeners' lumbago; fatigue from excessive or unaccustomed exercise, or from postural abnormalities such as kyphosis or flat feet;

(c) infection: acute, as in influenza, sandfly fever, rubella, or many other infections; or chronic, from a focal sepsis; 
(d) irritation of nerve roots by tumours of the cord or prolapsed intervertebral disc;

(e) general metabolic disorder, such as gout;

$(f)$ endocrine disorder, such as hypothyroidism and possibly hypopituitarism;

( $g$ ) increase of fibrous tissue, e.g. the susceptibility to rheumatic pains of scar tissue in old injuries, the tendency to "stiffness" in old age, and possibly also the increase of fibrous tissue as a result of previous rheumatism.

Some of these are external and environmental, others internal and individual factors. They may act in combination, so that an attack of non-articular rheumatism may be due to an environmental agency acting on an individual constitution which is predisposed to rheumatism either by hereditary endowment or by acquired bodily changes due to the effects of either the same or of other environmental agencies in the past. That two or more of these factors, internal and external, are involved is often suggested clinically by the fact that the same environmental cause may affect different individuals in different ways, or the same individual in different ways on different occasions.

\section{Possible Mechanism of Local Tissue Change}

Elliott (1944), by electromyographic studies in muscles supplied by nerve roots irritated by prolapsed disc or spinal tumour, found that tender spots consisted of small groups of muscle fibres in involuntary spasm, and said that " muscle spasm is considered to play a part in what may, for convenience, be called the rheumatic myalgias as well as the less common root syndromes ". $\mathrm{He}$ suggested also that sustained contraction of muscle impedes intramuscular circulation, and that the consequent anaemia may lead to fibrosis. Copeman (1943) suggested that acute infections like influenza may leave a legacy of latent " myalgic spots " which may later be activated by secondary factors, such as chill, to provide an attack of rheumatism. Copeman and Ackerman (1944), as a result of both biopsy and necropsy observations, reached conclusions "which seem to explain certain cases of fibrositis of the back, and it is believed, elsewhere". They considered that certain areas of fatty tissue were particularly affected, becoming oedematous and congested under the influence of chill, toxaemia, etc., forming small herniae through fibrous tissue, which may then become chronically strangulated and form tender nodules. They stated that such changes probably represented a comparatively advanced stage in the process, and that " to explain the minor and less localized degrees of fibrositis almost universally experienced at one time or another we need not postulate actual herniation of the fat tissue ". Lewis (1938) has shown the constancy of the quality of muscular pain as a result of such varying stimuli as limitation of the circulation, electrical stimulation, injection of isotonic acid solution, hard squeezing, or light pressure on a muscle 
previously fatigued. Kellgren (1938) showed that pain from muscle is always diffuse, and often referred, the referred pain being associated with referred tenderness of deep structures. Kelly (1945) described this diffuse pain and tenderness as being due to reflex nervous impulses from myalgic spots occurring at particular "sites of election" at musculo-tendinous junctions. In a later paper (1946) he suggested that these myalgic spots were themselves largely due to reflex nervous influences.

There may be more than one mechanism of production of rheumatism in muscle and fibrous tissue, and it seems still more likely that there are different stages in the process, so that the actual tissue changes may vary according to the aetiological factors, their combination, their severity, or their length of duration, but may produce the same symptoms in the patients, though with possible variations in the objective physical signs.

\section{Published Observations on Psychological Factors in Relation to Non-articular Rheumatism}

In an analysis of morbidity statistics among insured patients, Halliday (1935, 1938) stated that $40 \%$ of those labelled rheumatism were suffering from psychoneurotic illness. The same author (1937) suggested that considerable insight into aetiology could be obtained by investigating many cases labelled rheumatism in terms of emotional reaction, of localized physical inferiority, either inherited or acquired, and of the symbolic representation of emotional attitudes by means of bodily symptoms (e.g. lumbago as a symbol of a " rigid independence "). Gordon (1939) drew attention to emotional derangement of autonomic imbalance, acting through the thalamic and hypothalamic centres, but also stressed symbolism as the basis of these symptoms, and wrote of the " hysterical simulation of rheumatism ". Hurst (1943), in what he described as an " essay in debunking" on the treatment of sciatica, gave examples of hysterical features; and Jackson (1943), in a very careful analysis of 100 cases of sciatica examined by expert neurologists, stated that " ruptured intervertebral disc, fibrositis, and neurosis are the three states of greatest importance in the causation of chronic sciatica in young people". Fetterman (1940) described "vertebral neurosis", in which he considered that long stretches of the erector spinae might be modified by emotional tension and produce symptoms, again symbolic in manifestation, such as the bent back inviting pity for one who cannot carry on under the laborious load of life. Hutchison (1942) found precipitating or aggravating psychological factors in 6 out of 54 cases of fibrositis, but distinguished these from bona fide fibrositis, and considered that two of the three signs-well-defined tenderness, spasm, or noduleformation-must be present to establish this bona fide. Boland and Corr (1943) described as "psychogenic" approximately one-third of a series of 450 cases of disabling "rheumatic" conditions both of joints and muscles in. United States soldiers. Heaton (1944) found that 26 out of 53 Canadian soldiers with joint 
pains had no objective signs of disease but evidence of psychological disorder; non-articular rheumatic pains were described in 14 of these patients.

Ellman and others (1942), in a biographical study of 50 patients, described what they called " the psychodynamics of complaints mimicking true fibrositis". They stated that a complaint of vague shifting pains was suggestive of underlying emotional disorder, while " strictly localized pain points to the presence of organic change ". Thirty-five of the 50 patients were found to have significant psychological disorders, and the ratio of those with localized pain to those with vague pains was smaller (13 to 22) in these patients than in the rest of the series (in which it was 13 to 2). Nevertheless 13 out of 35 patients in this series did have localized pain.

Flind and Barber (1945) found 42 cases of generalized muscular pains of psychoneurotic origin in a series of 120 patients investigated in a rheumatic centre in the Royal Air Force, and they described the condition as " not a physical one but entirely a psychogenic reaction". Halliday (1944) considered that the onset or the recurrence of certain cases of "true fibrositis" might be precipitated by emotional upset. The general tendency, however, of many of the writers just quoted is to differentiate between the pains of psychoneurotic origin and those of "true rheumatism" or fibrositis.

\section{Some Observations on Muscular Pains in Patients with Psychoneurosis}

Many of the papers just quoted gave some estimate of the percentages of neuroses found in groups of patients presenting with rheumatic pains. The present investigation proceeds in the opposite way and deals with the prominence of muscular pains in a series of patients with psychoneurosis. It forms part of a survey of 183 adults with psychoneurosis seen in a general practice during four years. There was a wide variety in the presenting symptoms of these patients. Some had demonstrable structural lesions, such as peptic ulcers, but these were included only if there was strong evidence of an emotional factor in their production, and when there were also other symptoms and signs likely to be emotionally determined in the same patients. Against the background of the other complaints such lesions may appear to be mere episodes in the full context of the life history, just as the fixed furrows on a man's brow may be but one part of an apprehensive outlook on life. It seems of little value to classify these patients according to their symptoms, which are so varied and multiple. Terms such as " cardiac neurosis" are for this reason both useless and misleading. It is difficult also to state the presenting or predominant symptoms in individual patients, especially when these are observed over a fairly long period. This is perhaps especially noticeable in general practice as compared with hospital work-a longitudinal as compared with a cross-section view of the patient. It seemed of interest, however, to note the incidence of some of the commoner groups of symptoms found in the whole series. 


\section{COMPARATIVE INCIDENCE OF SOME SYMPTOM-GROUPS in 183 Patients with Psychoneurosis}

Muscular pains were described by 87 patients $(47 \%)$; headaches by $72(39 \%)$; gastro-intestinal symptoms (including 14 cases with peptic ulcers) by $70(38 \%)$; subjective mental symptoms, described as depression, anxiety, or nervousness, by $49(27 \%)$; insomnia by $32(17 \%)$; skin complaints by $29(16 \%)$.

The 87 patients with muscular pains included some in whom these pains were the chief, and in some cases the only complaint when first examined, and all these had some degree of muscular stiffness and tenderness. In most of the patients the muscular pains were accompanied by the other symptoms. Many who described these pains as part of their previous history said that their muscles had been stiff and tender at the time. In others the description was more vague, but in these the attacks were either frequent or prolonged.

\section{Other Complaints With - Which Muscular Pains were Associated}

Symptoms most commonly found, either coincident or more often in sequence with muscular pains, in the 87 patients were as follows: gastro-intestinal symptoms (including 7 with objective evidence of peptic ulceration), 43; headaches, 41 ; cardiovascular disorders, 39; skin complaints, 15 (psoriasis 6, alopecia areata 5, urticaria 2, pruritus vulvae 2); insomnia, 12 . Other complaints in a smaller number of patients were tremors, sweats, dysmenorrhoea, and frequency of micturition.

Halliday (1943) has pictured as a "repertory of diseases" the tendency of certain affections to coexist or follow each other in the same patient, and fibrositis and duodenal ulcer were one of the associations he described. Copeman (1939) referred to the association " in a very large majority of cases" of fibrositis with dyspepsia, and also stated that "the type of patient with sciatica is the typical duodenal ulcer patient"; although he gave no evidence in support of these observations, they are significant in the present context, especially as he was not referring to psychological factors in this connexion.

The large number complaining of headaches suggests that some of them may have been of the rheumatic type described by Cyriax (1938) as due either to referred pain from cervical muscles or to changes in the aponeurosis of the scalp.

\section{SITE OF PAIN}

Pain was described as being in the chest in 43 cases; in the lumbar region in 36; of sciatic distribution in 7; more vaguely described in the upper or lower limbs in 31 ; in the neck in 17 . The pains were predominantly unilateral in 51 cases, in 44 of which they were mostly left-sided and in 7 right-sided. At least 2 of the 7 patients with predominantly right-sided pains were left-handed. 


\section{Note on Left Thoracic Pain}

Twenty patients in the series complained of pain of the type sometimes described as praecordial or inframammary, but 12 of these also had rheumatic pains in other sites. Baker (1942), in a series of 52 patients with inframammary pain, found that the majority complained also of pain and stiffness elsewhere, but that these other pains were usually found only on enquiry, the " heart" pain having assumed most immediate importance in the patients' minds. Baker also described that $45 \%$ of these patients showed some tenderness on palpation. Wood (1941), investigating the left thoracic pain in "effort syndrome", found this pain in $78 \%$ of a series of 200 cases. In $25 \%$ of these there was pain also on the right side of the chest, and $57 \%$ had pains described as "cramps" in other parts of the body. He described this pain as arising in local muscular and fibrous tissue. This pain is even sometimes described by writers as "pectoral fibrositis", and Copeman (1939) affirms the presence of small tender nodules " in the praecordial area in certain cases of pseudo-angina ". From the clinical characteristics of this pain, and from its frequent association with pains on the right side of the chest and in other muscular regions, there seems, therefore, to be good evidence to suggest that it may be grouped with the other muscular pains under consideration.

\section{Three Case Histories}

\section{CASe 1}

A farm-labourer of 35 for eight years had frequent and long periods of incapacity from lumbago, sciatica, and pains in chest, limbs, and neck. The panel card repeatedly notes that the left side was most affected. At a time when the patient was away from work for over three months with lumbago, the muscles were very tender and stiff, but the lumbar and sacral vertebrae showed normal $x$-ray appearances. A prolonged course of radiant heat and massage in hospital resulted in little improvement. The man had a previous history of frequent abdominal pains, headaches, and tachycardia, and these complaints to some extent alternated with his rheumatism.

$\mathrm{He}$ had a surly, miserable expression and deeply furrowed brow, was very reserved, and at first stated that his only worry was his rheumatism. He later admitted great resentment against his employer, whom he accused of a bullying, overbearing manner. He would have liked to answer the employer back, but was afraid of losing his job, and also that his widowed mother, to whom he was much attached, might have to turn out of their cottage, which was tied to the farm. He seldom went to public houses or cinemas, and said he had no interest in girls. He showed much relief after discussing the problem of his work, and his resentful expression cleared for a time. But behind this current problem lay a much deeper antipathy to farm work. He said that he always disliked the work, but had to go on the farm in the first place because " it would be made unpleasant for his father " if he didn't (again owing to the tied house). His father had died very suddenly over eight years previously, and the son's illness began soon after this. He admitted that his father's death was a great shock to him, and he reproached himself that he did not say good-bye to him before he went to work that morning. But behind this reproach was a deeper sense of guilt, based on a great deal of antagonism to his father. In the words of an older sister, " he and father were not very good friends, you see father didn't like the way my mother spoiled him when he was a boy".

Great improvement followed a change of work, and for the last two years he has lost no work by illness: 


\section{CASE 2}

A married woman of 34 had a four years' history of rheumatic pains, and had had various forms of treatment, including analgesic local injections. The most persistent pains were in the lumbar region, but she also had pains in the shoulders, neck, and legs, and soreness, which she said she could " pin-point ", above the breasts. The left side was more affected than the right. She also complained of migrainous headaches, dysmenorrhoea, "palpitations" on slight exertion, constipation, lassitude, and depression.

She was vivacious and humorous, used to be athletic, and "hates to be beaten over anything" but since her rheumatism she could not lift weights and dared not garden. She had been married eight years, was relatively frigid, and coitus was now infrequent. She had a great fear of pregnancy, based largely on the warnings of her mother. "It seems a wretched thing to say, but she always seems to enjoy talking of the dangers of childbirth." The mother also exaggerated the moral dangers besetting her daughters as girls: "Never trusted us when we were courting." The patient had a very strong affection for her father, and was rudely shocked by a suspicion of his infidelity to her mother shortly before his death. She felt her mother had been gravely wronged and had to take her side, but at same time hated to see her mother who "had always been so suspicious of this kind of thing " morally exalted over her father. "She seemed to have been looking for this sort of thing all the time and now she has got it." The patient tried to disbelieve the allegations and to make every excuse for her father, but she never felt the same towards him again. "It seemed worse than if my husband had been unfaithful to me." She had very intense resentment against her mother, dating from earliest childhood memories, combined with fear of her and inability even now to hold her own with her in conversation. With this went a strong desire for her mother's affection, to which the latter did not respond: "Mother seemed cold to us as children - didn't seem to feel towards us as we did to her. I suppose she oughtn't to have had me." The patient had a strong resentment also against her only brother and his wife, whom the mother seemed to favour more than her daughters. She said that when talking about her brother she felt a tightness in her throat and stiffness in her neck. There was recent resentment at her mother's re-marriage: "It seems so unnecessary-we could have looked after her."

This was a small part of this patient's story. She was seen over a period of some months and showed very great resistance against discussing her attitudes to her parents, great fear of disloyalty in this matter, and also fear of allowing herself to realize the strength of her feelings, but eventually great relief and general relaxation of mental and physical tensions. She gained nearly a stone in weight and has now (1945) for over a year been working in a war factory.

\section{CASE 3}

An unmarried woman of 47 suffered for three months from lumbar and sciatic pains and recurrent pains in the neck, chiefly on the left side. Also during the last eight years she had a history of " tired heart", fainting attacks, and "chronic laryngitis". Two years ago she had an operation for "slipped kidney", and has felt worse since the operation. She previously enjoyed good health, but had attacks of " muscular rheumatism" when aged 18 and 26.

She was the second of a family of four, and was intensely jealous of a brother three years younger; she recalled her violent tantrums when she saw him in her mother's arms. The usual treatment for these tempers was to have her head forced back by a spongeful of cold water applied to her face by her grandmother. She used to dread this punishment, and often had dreams in childhood-as well as waking sensations of suffocation-of having her head fixed back in a vice, and a clutching sensation in her throat. She remembered once, after one of her tantrums, being taken by her grandmother to see her mother lying apparently ill on her bed. On being told, "Look what you've done to your mother", she was very remorseful and tried to kiss her but was refused. The " muscular rheumatism" at the age of 18 came during a time of 
great resentment against her father, who was then drinking heavily and bringing poverty to the family. She was working against great odds to train as a teacher, and realized bitterly that she was the only one of her family to have been denied a secondary education. The second attack when 26, followed the death of her mother after she had nursed her during a very trying illness for two years, having had to give up her job to do so. She suffered much guilt over her imagined neglect of her mother, and a heavy sense of responsibility mixed with guilt over the administration of morphia tablets prescribed by the doctor. At times she felt the muscles of her neck "all matted up" and used to "savage" them with a kind of self-massage. After this a long and unhappy engagement was finally broken off, largely owing to the antagonism of the prospective mother-in-law. The patient then rather desperately threw her energies into various jobs and kept out of doctors' hands for thirteen years. The present symptoms came on while she was housekeeper to a widower, in whose house she was much imposed upon, and where she developed deep antagonism to his very unmanageable boy. Various dreams and associations linked this boy with her young brother, and revealed violent death-wishes. She had also fierce resentment and death-wishes against her mother in many dreams. She was surprised and very shocked as the degree of her aggression was gradually interpreted to her. One attack of pain and stiffness in her neck came during the course of treatment after she had been reading of some Fascist atrocities in Rumania, and she had felt compelled to brood over this for a few days. This also made her recall that when a girl she had had the same feelings and muscular pains after reading about the Spanish Inquisition.

Great improvement followed her realization and free discussion of her aggressive impulses; she appeared also to have much relief after relating many dreams of very aggressive and sexual content, and after a partial interpretation of some of these, she not only had a diminution of pains, but she volunteered that she no longer felt " a drawn, tense feeling in the face" and that she slept in a relaxed attitude whereas she used to sleep in a state of clenched flexion. She described a " loosening out ": "I feel I'm clearing a space around myself." When seen again after a period of four years, she declared herself better than she had felt for many years; she had gained weight, had a much happier facial expression, and had been working without interruption from sickness for four years.

\section{Discussion}

In the investigations and case histories just recorded the description of " muscular pains" was used, thus leaving open the question whether these represent " true rheumatism" in the sense of the definition quoted at the beginning of the paper, namely, a condition with a local fissue change.

If there is no local peripheral change the only likely explanation of these pains would be that of a central alteration of perception, or a lowering of the threshold to pain.* This mechanism would represent that of a pure conversion hysteria, comparable with the type of case with hysterical anaesthesia or hyperaesthesia. This type of case is, however, generally acknowledged now to be rare in such a series compared with the various types of anxiety states, many of which may have presenting somatic symptoms. The high incidence of these pains in the present series of 183 patients was altogether out of proportion to the incidence of the typical case of conversion hysteria. The common accompaniment of other

\footnotetext{
* The rather facile acceptance of the view that psychoneurotic individuals are hypersensitive to pain has been challenged by a recent experiment, in which psychoneurotic subjects of low-back pain were injected with a silver nitrate solution. The pain, limitation of movement, and tenderness following these injections lasted from five to six days, and showed no prolongation when carefully compared with the results of similar injections in normal controls. I am grateful to Dr. J. Paulett for permission to quote this observation from his paper, which is not yet published.
} 
symptoms and signs, such as dyspepsia, headaches, and tachycardia, suggested also that in most of these patients the fundamental disorder was based on a state of anxiety with its physical accompaniments, and this was supported by the psychological investigations.

Although the type of pure hysteria is comparatively rare, however, the conversion mechanism may more often be found in conjunction with anxiety symptoms. Certain bodily changes may occur primarily as physiological accompaniments of emotion, but may also to some extent be substitute expressions of the emotion, which partially relieve and replace it. Thus a muscular tension which may be part of a pathological emotional reaction of infantile aggression may then form a substitute for its direct expression, as a rigid unyielding posture symbolizing an equivalent mental attitude. These symbolic expressions may still, however, be based on local tissue changes in the muscles themselves. It will be shown later that the predominance of symptoms on the left side may, in the same way, have a primarily physiological and secondarily symbolical explanation.

\section{The Psychopathology}

The case histories recorded were typical of many others in the series. In what way were these patients ill? All three were faced with hard circumstances in the form of difficult problems of personal relationships. The first had uncongenial work under a hostile employer and found difficulty in altering this without upsetting his home and mother. The second patient had a physically unsatisfactory marriage and a lonely frustrated social life. The third patient was approaching the menopause, disappointed in her prospects both of marriage and of an interesting career, and out of sympathy with the more favoured members of her family. In all three patients, however, the contemporary emotional problems were closely linked with earlier conflicts in the same field of personal relationships and extending right back to what might be regarded as the developmental stage of their capacity for these relationships, within their own families, in early childhood. Emotions of resentment rather than of fear seemed most prominent, but traced back to its earlier manifestations this resentment was strongly mixed with anxiety, in the way that anger and fear are often mixed together almost as one emotion in early childhood, as in certain animal behaviour. Like most of the other patients in this series, it was not easy to place them in a rigid psychopathological classification as patients with anxiety states, conversion hysterias, etc.; but at the basis there was a state of anxiety associated with deep emotional conflict which lay behind the contemporary mental problems of these patients.

\section{The Question of Psychosomatic Relationship}

"Psychosomatic" medicine is a study based on supplementing the usual clinical methods of examination by psychological methods such as those just described. It implies no dichotomy between mind and body: it is the method of 
approach which is two-sided, not the object of the study. The following discussion of "psychosomatic relationship" is an attempt to correlate the findings which result from these two methods of approach.

Even those most sceptical of psychosomatic conceptions recognize that emotions are commonly accompanied by bodily changes of the kind demonstrated by Cannon's outstanding work (1939). Such bodily changes are easily seen to be biologically appropriate, mobilizing the full resources to deal with the circumstance which arouses the emotion, preparing, for example, for fight or flight in the face of danger. It is not surprising that skeletal muscles should be affected in this way. The very word emotion (movement from) suggests muscular preparedness. Muscular tension is " an expression of the personality's habitual defences " (Dunbar, 1938). Apart from voluntary tension and "bracing up", there are certainly involuntary changes of muscle tension, the skeletal muscles being governed at both levels, cortical and thalamic (Cannon, 1939). Darwin (1872) described the variety of some of the muscular tensions in animals which he called "the language of the emotions". In the human infant also expressive movement and gesture has been described as a "pre-verbal language" (Wolff, 1945). This language is, however, limited to convey only the current feeling-tone of the individual, or, as we might call it, "the mood of the moment ". In adult man the development of the verbal language faculty largely supersedes the "language of the emotions". A sign or a series of sounds then serves as a substitute for an object or a concept and can thus be used as a means of transferring ideas rather than mere feeling-tone to a second individual. Speech then comes to form "a manifestation of partial motor inhibition" (Sherrington, 1933). In psycho-analytic terms this process corresponds with the development of the ego, which " by interposing the process of thinking secures a postponement of motor discharges and controls the avenues to motility" (Freud, 1923). Personal relationships based on this faculty constitute what Burrow (1941) has called a " socio-cortical segment of reactions", as compared with the "phylo-thalamic segment" which governs the organism's primary adaptation to its environment.

Now psychoneurotic reactions have been defined as " abnormal mental states ... which are the result of persistent mental conflict over personal relationships, past or present, in regard to others or to oneself " (Gillespie, 1942). This psychopathology of personal relationships nearly always extends back to their developmental period in the first few years of life (as was illustrated in the 3 case histories described). And during this period cortical activity is still immature and the child is dependent on emotional expression controlled by thalamic centres. The psychoneurotic adult, therefore, whose response to a situation of difficulty or danger largely reactivates earlier conflicts in the field of personal relationships, tends to react in this "phylo-thalamic" rather than "socio-cortical" fashion. As a part of this emotional response many bodily changes may occur which are quite inappropriate to the current circumstances. The emotion, including its associated bodily changes, is an anachronism. The result is something quite 
different from what is commonly implied by the effects of worry, grief, or shock. It is an essentially pathological condition: a pathological emotional state including, among other bodily changes, a pathological muscular tension. There are four reasons why this tension should be pathological. The first is its anachronistic nature, already mentioned. Unusual muscle groupings may be employed, reproducing tensions and postures to which adult human adaptations have made the individual unaccustomed. Secondly, these tensions may be of more prolonged duration. The patient with psychoneurotic conflict is often faced by difficulties and dangers which are inescapable because they are internal rather than external. Far from allowing relaxation, sleep often leads to an increase of this tension; hence very often the symptoms are worse on waking. Thirdly these tensions are, owing to the characteristics of neurotic conflict, incapable of adequate discharge in action. Fourthly these tensions may sometimes be even more forceful than voluntary muscular contractions. It is well known that people who grind their teeth during sleep cannot voluntarily reproduce such violent contraction, and Saul (1941) suggested that contraction of the trunk muscles during sleep may be as strong as this.

It seems reasonable, then, to suggest that these pathological tensions may be as aetiologically relevant as chill, fatigue, infection, and the other suspected causative factors of non-articular rheumatism which have been described; and as more than one of these factors, internal and external, may contribute to a given case of rheumatism, so the emotional factor may be combined with others or may be the sole or predominant cause. Corresponding with the degrees of severity and the length of duration of mental conflicts there may be a wide range in the severity of the rheumatism, from transient and vaguely defined pains to chronic and more localized regions of pain, stiffness, and tenderness. But the same range may also be found in rheumatism provoked by other factors such as chill or infection. The muscular pains following chill or unaccustomed exercise may be vague or transient but none the less "rheumatic" in the sense that they are based on local tissue changes, even if no fibrous nodules can be demonstrated. It was shown also that even those writers who describe the pathology of fibrositis with most precision suggest that there are stages in this process (such as abnormal spasm, increased exudation, or altered local metabolism) short of the fully developed condition.

\section{GREATER INCIDENCE ON THE LEFT SIDE}

This question is of interest both for its own sake and also for its bearing on the general mechanism of psychosomatic rheumatism. I have already shown that 51 out of 87 patients complained of pain more on one side than the other, and that 44 had left-sided pains and 7 right. Halliday (1937) in a series of 21 patients with neck and shoulder pains found 13 left-sided compared with 1 right. In a later paper, also, he described a characteristic left shoulder pain which he called "the neuritis of deprivation" owing to the frequency with which it is found to 
follow misfortune or " sinister events" (Halliday, 1941). Halliday explained this in terms of symbolism. The symbolic association of the left side in folk-lore and myth, superstition and dreams, with disaster, grief, and various forms of evil, is well known, and it is acknowledged by the use of the word "sinister" as opposed to "righteous". But while accepting the fact of this symbolic association, it might be possible to explain rather more precisely why and how these symptoms develop on the left side and incidentally also to bring some light on the question of how this symbolic association has arisen.

First it may be recalled that 2 patients in my series whose pains were chiefly right-sided were left-handed individuals. In Halliday's series the one patient with right-sided pains was described in the case history as being ambidextrous, though no comment was made on this. Now, since so-called ambidextrous individuals are usually left-handed people who have been trained to become right-handed, Halliday's observation supports my own figures in suggesting that the factor of importance in unilateral psychosomatic rheumatism is not the left side as such but the non-dominant side. It seems very probable that habitual muscular tensions differ between the dominant and non-dominant sides of the body. This may well be associated with facial asymmetry, which has been illustrated by Wolfe (1933) who, by making reconstructed portraits of double left-sided and double right-sided faces, showed that the right face expressed the individuality, changing from year to year, while the left side was more instinctual and changeless, and representative more of the species than of the individual. It has been noted also that facial asymmetry is more pronounced in very strongly left- or right-handed individuals (Ogden, 1929). Wolff (1945) showed that the gestures of the right hand express individual, voluntary impulses while those of the left hand betray the unconscious instinctive reactions. Now this dominant laterality is, of course, dependent on the same unilateral cerebral dominance which "forms the hallmark of the language faculty" (Orton, 1937). Russell Brain (1945) states that "we can be reasonably sure that the dominance of one hemisphere was a precondition of symbolic thinking and expression which at the psycho-physiological level distinguishes man from all other animals, and we may guess that when human culture first developed man was already both able to speak and predominantly right-handed ".

It has been already shown that it is the development of language which, superseding the merely thalamic expression of emotion (including postural tensions), enables the normal human adult to exert a cortical restraint on his thalamic reactions, and thus to deal more adequately with adult situations of difficulty or danger. In the same way, and at about the same time in the child's development, a dominant laterality, expressive of the individual and under cortical control is superimposed on and largely supersedes a symmetrical muscular tension-pattern under purely thalamic control, which belongs to the infantile, animal, " phylo-thalamic" level of reaction.

When, as in certain psychoneurotic reactions, these early tension-patterns are 
revived, the non-dominant side of the body may be most affected, because it is less influenced by the cortical impulses which habitually modify the thalamic reactions on the dominant side.

This, then, is suggested as a possible explanation of the greater incidence of psychosomatic rheumatism on the non-dominant side of the body. It might also explain the origin of the symbolism which links the left side with the more primitive instinctual level of the mind and with the idea of evil which is evoked by man's deep-seated fear of his crude instincts and of their symbolic representations, such as Pan and Satan, which signify not only the "temptations" afforded by these instincts but also the dangers which they may provoke in the way of punishment.

\section{Summary and Conclusions}

Muscular pain was a prominent symptom in 87 of a series of 183 patients with psychoneurosis $(47 \%)$.

In 51 of the 87 patients the pain was mainly unilateral (44 left-sided and 7 right). At least 2 of the 7 patients with right-sided pains were left-handed.

Three case histories were described to illustrate that these patients suffered from persistent conflicts over personal relationships. These conflicts extended back to the developmental stage of the capacity for these relationships, before the acquisition of symbolic speech, and at a period when emotional expression, under purely thalamic control, includes changes in muscular tension.

Muscular tensions thus later reproduced may be pathological because they are anachronistic, abnormally prolonged, and incapable of discharge in action.

It is considered that these pathological tensions may rank with other factors such as chill, infection, or physical strain in promoting local tissue changes. They may act alone or in combination with these other factors.

It is suggested that the common left-sided incidence of these pains may be due to a relative freedom of the non-dominant side of the body from the cortical control which modifies the thalamic reactions on the dominant side. This control develops in close association with the speech faculty which largely supersedes the more primitive response to danger.

This study concludes that the muscular pains of patients with psychoneurosis are on the balance of probability due to peripheral changes rather than to central alterations of perception. They may, therefore, be justifiably described as "rheumatism" and, more specifically, as psychosomatic non-articular rheumatism.

I am grateful to many who have read and criticized the drafts of this paper, and especially to Dr. J. L. Halliday.

\section{REFERENCES}

Annotation (1946). Brit. med. J., 1, 134.

Baker, D. M. (1942). "Cardiac Symptoms in the Neuroses." London.

Boland, E. W., and Corr, W. P. (1943). 'J. Amer. med. Ass., 123, 805.

Brain, W. Russell (1945). Lancet, 2, 837.

Burrow, T. (1941). Psychosomat. Med., 3, 174. 
Cannon, W. B. (1939). " Bodily Changes in Pain, Hunger, Fear, and Rage," 2nd ed. New York.

Copeman, W. S. C. (1939). " "The Treatment of Rheumatism in General Practice," 3rd ed. London. (1943). Brit. med. J., 2, 263.

and Ackerman, W. L. (1944). Quart. J. Med., $13,37$.

Cyriax, J. (1938). Brit. med. J., 2, 1,367.

Darwin, Charles (1872). "“The Expression of the Emotions in Man and Animals." London.

Dunbar, H. F. (1938). " Emotions and Bodily Changes." New York.

Elliott, F. A. (1944). Lancet, 1, 47.

Ellman, P., Savage, O. A., Wittkower, E., and Rodger, T. F. (1942). Annals of the Rheumatic Diseases, $3,56$.

Fetterman, J. L. (1940). Psychosomat. Med., 2, 265.

Flind, J., and Barber, H. S. (1945). Quart. J. Med., 14, 57.

Freud, Sigmund (1927). " The Ego and the Id." Translated. London.

Gillespie, R. D. (1942). " Psychological Effects of War on Citizen and Soldier." New York.

Gordon, R. G. (1939). Brit. med. J., 1, 1,165.

Halliday, J. L. (1935). Ibid., 1, Suppl. 85.

- (1937). Ibid., 1, $213 ; 264$.

(1938). Ibid., 2, 11.

- (1941). Ann. intern. Med., 15, 666.

- (1942). Brit. med. J., 1, 164.

- (1943). Lancet, 2, 692.

- (1944). Practitioner, 152, 6.

Heaton, T. G. (1944). Canad. med. Ass. J., 50, 515.

Horder, Lord (1941). "Rheumatism. A Plan for National Action." London.

Hurst, A. (1943). Brit. med. J., 11, 773.

Hutchison, J. H. (1942). Glasg. med. J., 137, 33.

Jackson, W. P. U. (1943). Brit. med. J., 11, 776.

Kellgren, J. H. (1938). Ibid., 1, 325.

Kelly, M. (1945). Annals of the Rheumatic Diseases, 5, 1.

(1945-46). Ibid., 5, 69.

Lewis, T. (1938). Brit med. J., 1, 321.

Ogden, C. K. (1929). "“The A.B.C. of Psychology,” p. 249. London.

Orton, S. T. (1937). " Reading, Writing, and Speech Problems in Children." London.

Saul, L. J. (1941). Psychosomat. Med., 111, 190.

Sherrington, C. (1933). "The Brain and its Mechanism." (Rede Lecture.) Cambridge.

Wolfe, W. (1933). Character and Personality, 11, 168.

Wolff, C. (1945). " A Psychology of Gesture." London.

Wood, P. (1941). Brit. med. J., 1, 767; 805, 845. 